\title{
PERSPECTIVE ORIENTATION AND TIME DIMENSION IN STUDENT MOTIVATION
}

\author{
Isabella Pavelková \\ jfpavelka@volny.cz \\ Charles University in Prague, Czech Republic \\ Radka Havlíčková \\ havl.radka@yahoo.com \\ Charles University in Prague, Czech Republic
}

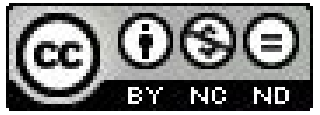

\begin{abstract}
Orientating oneself to time and work for the future is considered a substantive component of the autoregulative process. It is also important to students' mental regulation, which is closely related to academic success. The factor of time in human life has been approached in psychology in a variety of ways. We will focus primarily on those concepts which study time and detect time patterns in motivational dynamics of personality. The concepts of Joel O. Raynor, Torgrim Gjesme, Joseph R. Nuttin and Philip G. Zimbardo will be mentioned. Of Czech authors, the "perspective orientation" by Isabella Pavelková is presented. We will discuss diagnostic methods used in the measurement of time perspective, especially the Motivation Induction Method (MIM - J.R. Nuttin). Secondly, we will present selected researches that have been carried out in this field in the Czech Republic. These studies are focused primarily on issues related to the identification, development, and opportunities of internal assumptions conditioning the character and quality of an individual's future.
\end{abstract}

Key words: Time perspective, perspective orientation, motivation, time perspective diagnostic.

\section{INTRODUCTION}

The life of an individual, like that of the whole society, takes place in time. Time perception therefore plays a fundamental role in the selection and fulfillment of goals with significant implications for motivation, cognition and emotion of the individual. Not only the way people experience time, but also their ability to consciously and deliberately schedule and plan their lives, becomes a major mental regulation.

\section{TIME PERSPECTIVE: THEORETICAL BACKGROUND}

How we perceive ourselves and the world around us is mediated by the way we visualize, explain and use time (Levine, 2006). This idea was already at the centre of interest in ancient times, and was mostly disussed from the philosophical viewpoint. In the 1940s, it appeared as a separate topic in psychology. From the psychologi- 
cal point of view, the time factor plays an important role in cognitive, motivational and cognitive-biodromal theories.

In this chapter we are going to introduce the most important authors and their ideas. Our first major sources of information were books by European specialists in the field of the psychology of motivation such as J.R. Nuttin (and his colleagues) which led us to intriguing references to other authors. This method eventually snow-balled into what is now being presented here. The most recent articles were found thanks to online full-text databases (primarily ESCOhost).

The term 'time perspective' was first used in 1939 by Lawrence Frank. Three years later, Kurt Lewin incorporated this concept into his theorizings. He defined it as "the totality of the individual's views of it's psychological future and psychological past existing at a given time" (Lewin, 1935, p. 75). Actual behavior is, according to him, created by the current anticipation of future goals, not by the goal itself. Future time perspective is full of goals, dreams and expectations, which is understood by K. Lewin and his followers as a part of perspective, including the past, present and future.

Time perspective is closely related to motivation. This relationship has been discussed in cognitive motivational theories of achievement motivation since the 1950s. The major figures within this field are Victor Vroom, David McClelland, John W. Atkinson, J. O. Raynor and Jutta Heckhausen. An important model is Atkinson's theory of motivation performance (Hrabal, Man, Pavelková, 1989), which is based on the need to achieve success and the need to avoid failure. Both of these needs together form the basis of achievement motivation, which is further comprised of the level of attraction of achievement activities and subjective probabilities of the expected result. The individual's approach to task performance depends on the predominance of one of the two needs. Noteworthy, his/her motivating force and behavior is conditioned not only by the amount of these two achievement needs but also by their ratio.

J. O. Raynor, who developed Atkinson's theory, distinguishes two types of reason that lead the individual to an activity (Lens, 1981):

a) the effect of an activity is the ultimate goal itself,

b) the current activity serves as a means to approach further goals in the future

This brings us to Raynor's distinction between two types of path performance tasks: a noncontingent path consists of a series of steps (tasks), where anticipation of current success (or failure) has no effect on the chance to continue on the path. In contrast, in a contingent path the success of the first task is a prerequisite to achieve further goals. Failure, then, strips one of a chance to move on. A contingent path can be open or closed. If it is closed, goals remain invariant with practice and mastery of each step, whereas if it is open, the final anticipated goals change (they are replaced by new ones).

Although not uncitically, T. Gjesme followed in Raynor's footsteps. In the 1970s, he elaborated the concept of psychological distance and expectations. T. Gjesme points out two main factors that directly affect the psychological distances. One of them is a situational factor, which is the distance in time between the individual and a future goal; the other - a personal factor, which can be understood as a future time orientation of the individual (Gjesme, 1974). Future time orientation develops with age and gradually becomes a stable characteristic that allows individuals to antici- 
pate and deal with the future, that is, elaborate plans and to actively participate in creating their own future. It appears whenever there is some potential of achieving a goal, or at least a plan to achieve this goal.

It is arguably Nuttin's (1980) theoretical conceptualization of future time perspective that remains the most comprehensive. In his concept, future time perspective is conceived as a dynamic control of target objects that are placed in the future as a materialization of current needs (Nuttin, 1980). This concept is reinforced by the relational theory of specific human needs, where needs are understood dynamically, that is, as hierarchical patterns which link subjects with the outside world. Time perspective is filled with short-term and long-term goals that are mentally represented as objects in the mind of an individual. Goals are determined by time dimension, especially its extension, structure and depth. They are incorporated and located in perspective, and this perspective is built on the basis of motivational objects (and temporal characteristic of these objects).

An extended future time perspective is formed by planning distant goals, strategies and behavioral projects for achieving them. J. R. Nuttin and Willy Lens defined the extension of future time perspective as an individual interval (range) in time that a person usually takes into account while making decisions. Goals within this time range seem to be closer, brighter and more important.

We can see time perspective also in the context of a biodromal approach which examines personality and developmental changes throughout one's life. One of the first psychologists who was interested in this was Charlotte Bühler. She examined the structure and phases of life-long development as a dynamic and psychophysical unity. Lev Vygotsky emphasized the need to analyze personality not only in connection with the past but also the future. He expressed the view that both past and future are equally important for understanding an individual's personality (Vygotsky, 1976).

At the end of the 20th century, another scholar studied the problem of time perspective - P. Zimbardo. His theory combines motivational, emotional, cognitive and social processes. Time perspective is often regarded as a nonconscious process, whereby the flow of personal experiences is assigned to temporal frames (past, present and future), which help to give order, coherence, and meaning to those events (Zimbardo, 1999, p. 1271). Time frames are used not only in encoding, storing and recalling experienced events in the memory, but also in facilitating the process of forming goals (Zimbardo, 1999). This process is learned and modified by many factors, social, institutional and those connected with personality and family. With the passing of time, we tend to use in the process of decision making one of the three time frames more often than the others. Based on this process, thinking within a certain temporal frame becomes a personal characteristic, an individual style, thanks to which we can assume how the individual might react to certain situations.

We will briefly comment on the concept of perspective orientation formulated by the Czech scholar I. Pavelková (Pavelková 1985, 1990, 2002). This concept draws on the theoretical analysis of existing approaches (concepts) of time perspective and the goal dynamics of man in close connection with the issue of personality.

Perspective orientation is defined as a complex, relatively autonomous mental requirement for an active structuring of the future. It manifests itself in the form 
of distant goals that a person plans and strives to achieve. The basis of perspective orientation is formed by a cognitive need for structuring the future. Perspective orientation is a developmentally higher stage, which is preceded by short-term orientation. This kind of orientation is typical of younger students and is manifested by being bound to the immediate future and the tendency of individuals to set only short-term (immediate) goals. The transition from short-term orientation to perspective orientation is one of the key moments in the development of a child's personality. Specific actions have their place in the sequence of activities to achieve future goals. They are manipulated and planned in time and seen as a requirement for achieving goals in the future. The absence of a perspective orientation poses a threat that the action will be driven only by immediate impulses and desires. Perspective orientated individuals understand their future as a sequence of conditional goals.

Perspective orientation ranks among the important complex cognitive motivational factors. Using a simplified model ${ }^{9}$, we present the psychological principles of perspective orientation functioning.

Two main possible ways of structuring the future are distinguished in the model. We can refer to it either through the choice and realization of goals (a highlighted aspect is more motivational, afterwards possibly motivational free will) or by anticipating future events (cognitive aspect is highlighted). It is a relative solution: the two types are mutually dependent. In structuring the future through the selection and implementation of goals, there is a more direct impact on the individual's behavior and activity, that is, one becomes more involved. A motivational basis of perspective orientation entails the need to structure the future and it manifests itself as an increased tendency to plan for the future. We assume that it is constituted as a relatively generalized need. Further development and acquisition of experience with different incentives, and their adequacy in satisfying the needs of the individual, leads to its specification, which is related to specific areas in which the structuring of the future is realized. Ideas about the future mostly take on the form of wishes or goals and tasks, which an individual sets for the future. It is important whether an individual establishes goals for the near or distant future and whether there is a continuity between those goals or desires. The amount (intensity) of perspective goals (aspirations) is mostly determined by achievement needs. A specific selection (content) of wishes or goals, which an individual sets for the future, is determined by different structures of other needs. For example, if it is the need of prestige that prevails in some student's structure of needs, then perspective goals of this individual will probably have a utilitarian form (s/he will choose a high-status profession, regardless of the actual satisfaction derived from her/his job). Another example might be a perspective oriented student in whose structure of needs the need for affiliation is predominant. This student will probably choose those perspective goals which are linked to positive social activities. The process of setting perspective goals is very complex. It is determined by motivational and personality variables that are already cognitively processed (needs, hobby, value

Perspective orientation is a quite complex variable: individual dimensions can be manifested through qualitatively different forms, with a greater or lesser influence on the performance (behavior) of an individual. 
Fig. 1.: Model of perspective orientation.

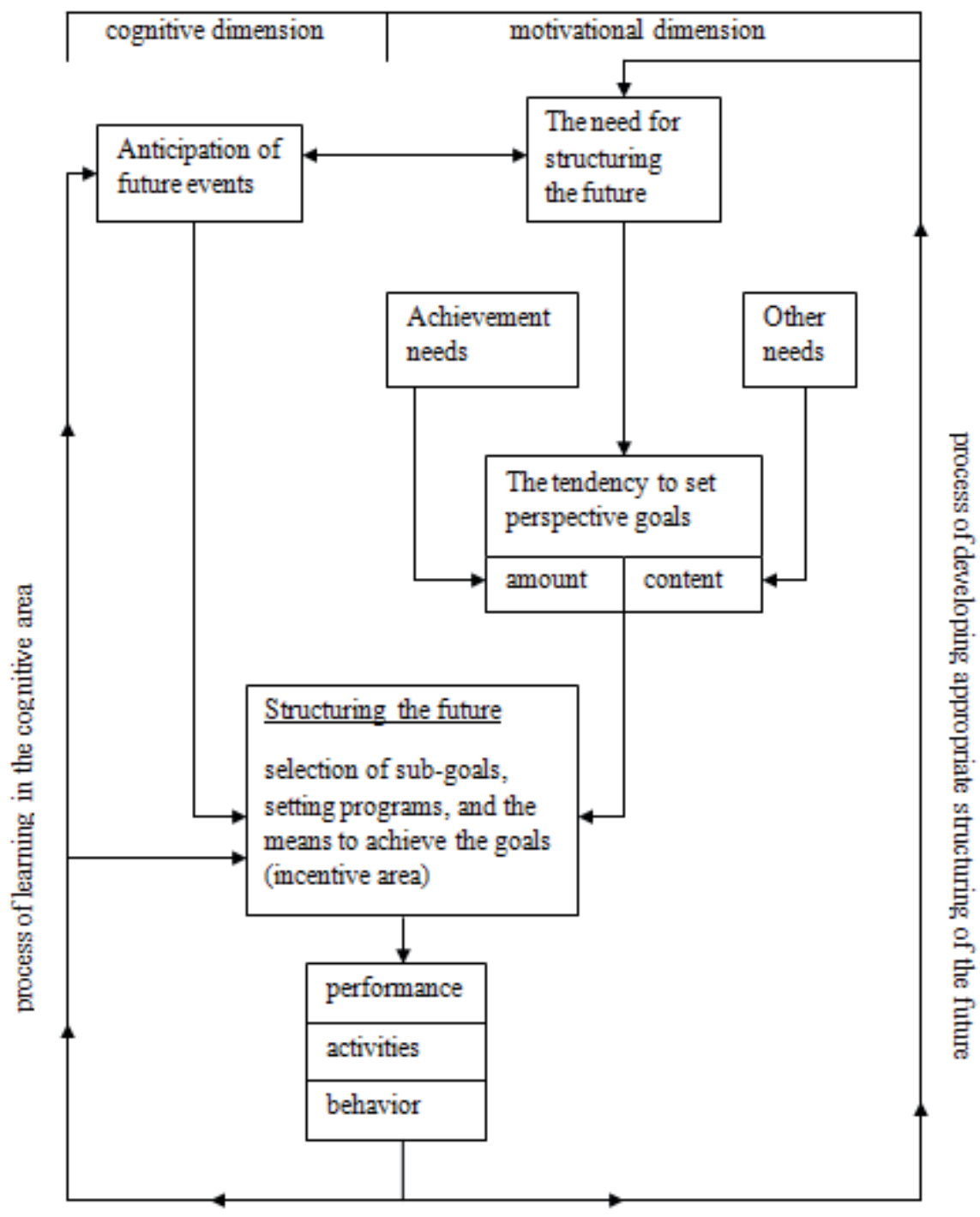

Source: Pavelková, 1990.

orientation, attitudes, beliefs and the level of self-esteem). One's anticipation of future events also plays an important role. The motivating force of perspective goals would be very weak if there was no plan or at least a general idea of how to achieve those goals. Such programs consist mainly in searching for appropriate resources and setting subgoals. We will not discuss the actual mechanism for determining 
perspective goals and their realization. Setting and realization of goals is described in Hechausen's Rubicon model, Figure 2.

Fig. 2.: Four phases of Rubicon model.

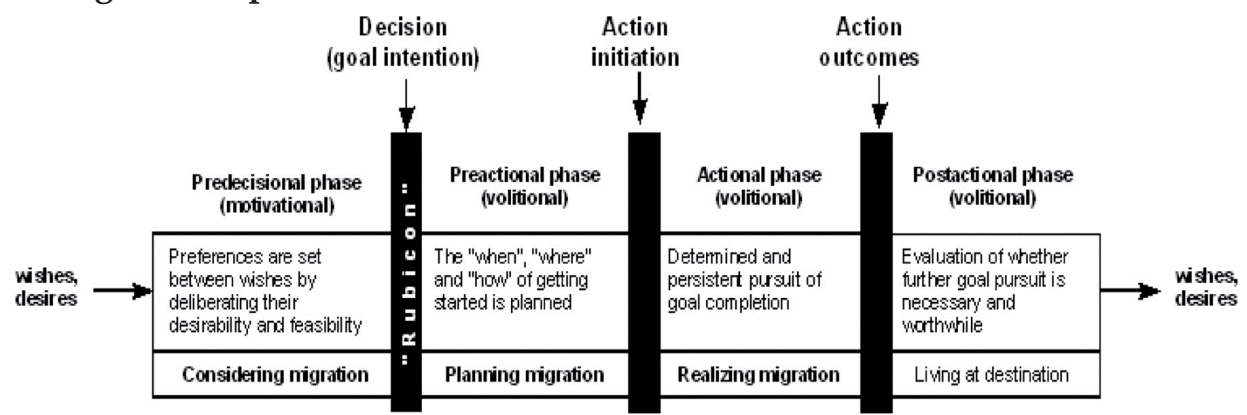

Source: Heckhausen 1991

In The Rubicon model, we can see that there is a gradual approximation (phase 3) to the perspective goal whose achievement marks a significant moment because it contributes to further development of the appropriate structuring of the future and the formation of cognitive processes (see model of perspective orientation).

Although in our definition perspective orientation is in the first place manifested through the selection and implementation of long-term objectives, it can also be seen as a reflected extended time ",horizon". It can have a significant impact on both the cognitive-affective activation of ideas and on the development of an individual's personality, without reflecting on the active conduct manifesto or construction of goals. In line with J.R. Nuttin (1980) we believe that the affect of an active time perspective and perspective orientation cannot be understood only in terms of overt behavior. Some memories and objects of motivation do not cause activity; but neither do they remain intact. It would be a mistake to consider perspective orientation in isolation, as divorced from the general cultivation of personality and its development. Various life events (alienation, health, etc.) can affect and often substantially interfere with our plans and projects. A person oriented toward the future should be able to alter his or her point of view of the future, which can always be seen as something probable (possible). On of the components of perspective orientation should be the ability to create temporal integration, which helps to perceive the future as an active continuation of the present and past.

\section{TIME PERSPECTIVE AND ITS MEASUREMENT}

Time perspective has been measured and operationalized in various ways and by many researchers. However, some psychometric problems still remain unsolved. As T. Gjesme speculaties (in Seijts, 1998), those problems stem from the diversity of definitions of the construct. Another problem is that the methods used vary in terms of their reliability and validity. Complications may, among other things, involve the fact that, for practical reasons, time perspective research is usually conducted solely at the level of ideas. It is, then, implicitly assumed that there exists a connection between thought and action. 
For a psychological evaluation of time perspective, we can use methods which can be classified into two groups: (1) one approach focuses on free expressions of probands (drawings, stories and other narrative structure), (2) the other one makes use of events in which the proband was engaged for some time, and which are therefore important for him/her. One disadvantage of the former approach may be that these motives may have a fantasy character without any subjective value.

Robert Kastenbaum used similar classifications, but he called the first approach "cognitive futurity" and the other one "personal futurity." Mark De Volder supplemented these two classifications (in his phraseology called a personal and impersonal contents) with a second criterion of knowledge or ignorance of the intention of the experimenter (direct vs. indirect). Thus we have four kinds of methods (Pavelková, 1985):

1. Indirect „impersonal" methods: The most common is the Thematic Apperception Test (TAT), in which participants are asked to complete a story which he sees in a picture. However, results are difficult to compare because of differences in the selection of cards, analysis of answers and guidance in volunteers in various studies. The Story Completion Test (SCT) works in a similar way. In the Incomplete Sentence Test, subjects are asked to complete 24 unfinished sentences. The Free Fantasy Process is different. Probands are located in a low-lit room opposite a blank wall, and their task is to narrate what has just crossed their mind.

2. Direct „impersonal" methods: Participants who undergo the Cottle's Circles Test have to imagine the past, present and future in the shape of circles, and then draw it, assuming that the size of the circles is directly related to the orientation of a time zone. Furthermore, this group includes the Future Time Orientation Scale and the Future Time Perspective Inventory. The Zimbardo Time Perspective Inventory would probably also belong to this group.

3. Direct "personal" methods: Experiential Inventory (Cottle) - participants are asked to ascribe the 10 most important events in their life to the distant or near past, the present, and the near or distant future. Similarly, R. Kastenbaum asked respondents to predict the possible events that may occur in their lives. This group may also include Nuttin's Motivational Induction Method.

4. Indirect "personal" methods: Interviews - participants are asked to tell something about themselves and then comment on a story.

In the studies we have carried out since the 1970s, we have tried most of these methods. We are especially interested in the Motivation Induction Method, Method of Style and the ZTPI. The formulation of our theory and specific research questions arising from the point of view of educational psychology led us to the construction of a new diagnostic method, which can examine the prevailing orientation (or short-term perspective orientation (Perspective Orientation questionaire). Below we offer a brief survey of some of the methods.

\section{MOTIVATIONAL INDUCTION METHOD}

Nuttin's Motivational Induction Method (MIM) is very sophisticated. This method is based on two principles (Nuttin, 1980): 
- Time perspective is constructed of motivational objects existing in the mental representation and therefore should be measured by identifying a temporal localization of these objects.

- It is not desirable to suggest specific temporal categorizations because we can evoke those objects in the mind of that person which are absent.

Although MIM is based on the task of completing sentences, it is not a projective method. The beginnings of those sentences are called inductors. They are written in the first person singular, and their main aim is to induce those objects that subjects may desire, wish, fear, try to avoid, etc. (Nuttin, 1980). In terms of their character, inductors may be divided into two basic groups: positive and negative. Completed sentences provide an overview of motivational tendencies and are appropriate for content analysis. It is assumed that these specific contents are virtually present in the mind of an individual and thus have an impact on his/her behavior (Nuttin, 1980).

Answers can be classified in various categories. Nuttin hoped that content analysis could lead to a better understanding of the internal structure of the subject's motivation. Nuttin (1980) distuinguished four types of elements in the coding system: the main motivational categories; different subcategories within a main category, which are coded by adding a second symbol; and a set of symbols that is used to code certain modalities characterizing the subject's motivation. Below we describe briefly the main categories:

1. Self: we code this when participants talk about their personality or its different aspects

2. Self-realization: used for activities that help develop the subject hersefl/himself (he or she wants to become some kind of person)

3. Realization: refers to work or school activities

4. Social Motivations: this group has three subcategories - contact with others, social reciprocity (subject wants something from others), and wishes and fears attributed to others

5. Cognitive motivations and exploration: we code this when the subject wants to understand, know, or explore something

6. Transcendental objects: refers to religion or philosophical and existential domains

7. Possessions: we can understand buying and possessing something as a special way of dealing with things, which is why it constitutes an entire category

8. Leisure: we code this if subjects talk about fun activities, relaxation, or sensorial pleasure (eating, drinking, taking drugs, etc.)

Coding of time analysis is not based on any estimates of the time in which events may occur, but on so-called "normal” or "average" (Nuttin, 1980) temporal localization, which is typical of the social group to which the proband belongs. Time localization obtained in the process of socialization characterizes the events and time when their occurrence is considered as normal (for example, in the pre-revolutionary period before 1989, it was normal for girls at the age of 20 to marry. Today the age of 20 is considered as an early age). The basic rule for the location of code is an objective consideration of the average time distance that the proband implicitly pla- 
ces on a motivational goal. It is also important to think about answers as a whole. It is therefore possible that the events come one after another because when probands formulate responses, they may be implicitly occupied with a previous inducer.

We can assemble time code in two ways (Nuttin, 1980). If the near future (days, weeks, months, and years) scale is composed of calendar units, the reference point is the present moment. If the time goes beyond one to two years, localization is vague and based on social units (study time, adult life, old age, references to the past, open present and life as a whole).

MIM was designed to study the adult population and the results of researche (Pavelková 1985, 1990, Havlíčková 2011) based on this method have revealed problems in its application to secondary and primary schools students. We think that it is necessary to modify the coding system so that it is more sensitive to the responses relating primarily to school. At the present, we see school as in four ways: (1) as a social environment (suitable place for meetings and communication); (2) as a tool for career growth (school as a preparation for career and professional growth); (3) as an environment where it is appropriate to saturate cognitive needs; and (4) as a potential source of worries and annoyances.

Actually we work on improvement of the MIM coding system in the project GAUK (Grant Agency of Charles University) ${ }^{10}$.

\section{ZIMBARDO TIME PERSPECTIVE INVENTORY}

P. Zimbardo and his colleagues developed a new method called the Zimbardo Time Perspective Inventory (ZTPI). This questionnaire contains 56 items rated on a five point Likert scale. It measures the following 5 factors:

1. Negative Past: This factor is characterized by a generally negative attitude towards one's own past, that is, either a potentially traumatic childhood with not-so-happy experiences or a negative reconstruction of non-traumatic experiences, or a mix of both. Research has shown that this factor is often associated with anxiety, depression or a low self-esteem.

2. Present Hedonistic: This factor refers to a hedonistic, risk-taking attitude to life. An individual focuses on present pleasures and does not take into account the future consequences.

3. Future: This factor pertains to those individuals who are focused on fulfilling their future goals, for which they are able to sacrifice their present satisfaction.

4. Past Positive: It represents a friendly, warm and sentimental attitude toward the past (e.g. remembering nice experiences and a nice atmosphere). Most of the questions within this factor are focused on fulfilling tasks. A temporal perspective (short-term or long-term goals) is not thematized in the test, though.

5. Present Fatalistic: This factor is typically a very desperate and hopeless outlook on life, which cannot be changed. It reflects a belief in predestination and uninfluenced fate. Presence is associated with the resignation of a better tomorrow. It was significantly associated with depression, aggression and anxiety.

10 The Grant Agency of Charles University, n. 904913, 2013-2015, main researcher Radka Havlíčková, co-researcher Lenka Stehlíková, supervizor Isabella Pavelková 


\section{THE PERSPECTIVE ORIENTATION QUESTIONAIRE}

The Perspective Orientation questionaire determines the prevailing perspective or short-term orientation of students. We have created several questionnaire forms. All of them have undergone psychometric validation (item analysis, factor analysis, reliability, construct validation questionnaire due to personality and intellectual variables and methods of temporal perspective - MIM, ZTPI). In the most recent psychometric validation, which took place in 2010, we screened variant PO-6, which consists of 30 questions (Crombach's Alpha $=0,74$ ). Our factor analysis confirmed the following factors. The first factor may be called the Perspective Orientation Factor. It brings together all the characteristics of the perspective orientation construct, namely, the need for structuring the future, the establishment of long-term goals and tasks, the implementation of plans and goals, and the tolerance to delay gratificaton. This factor could therefore be attributed to students who often think and plan, who are interested in and want to be clear about the future, and who tolerate delayed rewards. They do not mind the long-term challenges. Rather, such challenges motivate them. They still in a way seek self-improvement. They have plans and goals, and they want to go to college. The second factor brings together those students who have already decided about their career (are quite clear what awaits them), but are not so much concerned about the future. They are interested in a profession they have chosen, but they think that they can not rely on their will and do not want to go to college. The third and fourth factor unites students with a high tolerance to delay gratification. They have not yet decided what they would do after school, but they do not mind the long-term challenges. Simultaneously, they seek constant self-improvement (sensitivity to their personal development). The fifth factor unites students with initiator tendencies, that is, those who believe that they can affect their own future. This group of students does not care about nor plan for the future, and has multiple goals and choices to choose from, depending on the situation. They have already decided what they would do after school and believe that they can rely on their will (Pavelková, Purková, Menšíková, 2010).

\section{RESEARCH ON PERSPECTIVE ORIENTATION IN THE CZECH REPUBLIC}

Our theoretical goals aim at further development and completion of the student motivation concept, and at creating a promising concept of perspective orientation (Hrabal, Man, Pavelková 1989, Pavelková 2002). We also paid attention to the analysis of motivational patterns and students' approach to the future. We attempted to describe the current state of student motivation and perspective orientation of students in Czech schools.

Today the motivational concept is elaborated mainly in terms of effects that cause motivational problems among students in the school setting. For this reason, we mainly focused on the phenomena of boredom and fear at school. Long-term studies of these problems have resulted in the concept of the autodiagnostic teacher. This concept involves developed individual self-diagnosis strategies that teachers 
can use to reflect on their work.Clearly, the issue of student motivation and the relationship of students to the future are intertwined.

In the field of time perspective, our research mainly focused on issues related to the identification, development and seeking development opportunities of internal assumptions that influence the nature and quality of the individual's approach to the future (Pavelková 1985, 1990, 2002). It has been confirmed that perspective orientation is an important cognitive-motivational characteristic of students. Research has also shown that we can engage perspective orientation between factors, and thereby facilitating school performance. The importance of an older school age for the development of perspective orientation has been demonstrated both in terms of internal dispositions (development of the need for structuring the future and other needs) and in terms of external conditions (challenges). It turned out that at the end of primary school, but also in high school, there are significant differences in the level of students' perspective orientation. The resulting perspective orientation is becoming an important factor in self-regulation that coordinates immediate and motivating activities and other activities of students.

Although we cannot yet determine exactly how and why subjective temporal distance is the occurrence of each single event (goal) and what the perceived psychological distance (and thus efficiency) of future events is, a number of studies suggest that the main factors influencing this "psychological effectiveness of future goals" (motivational effect of future goals) are:

- Perceived value of goals for individuals

- Future time orientation (prospective orientation)

- Perceived instrumentality of current activities (learning) to achieve future goals

- Objective temporal distance of goal (event)

- Attribution tendencies of the individual

- Motivation - intention characteristics of the individual

All the factors mentioned above individually and specifically in mutual combinations affect the perceived psychological distance (and thus efficiency) of future events (goals). For example, it has been shown that despite the fact that perspective oriented individuals attach greater importance both to successful motivational goals that have long-term characteristics and to studying that they consider instrumental in achieving these objectives, the perceived instrumentality (also seen as important) is not identical with factors such as orientation to the future. A more detailed analysis has shown that some students realize the importance and instrumentality of studying for future goals, but they are not oriented to the future. On the contrary, there are students who are highly focused on the future and yet they do not realize the future instrumentality of current activities (learning).

Parallel monitoring of these factors as well as finding a more or less suitable constellation of these factors is therefore justified. Instrumentality of studying in terms of future goals (Pavelková 2010) has two aims that are related to academic performance (grades). Research has been conducted in primary and high schools. Based on our research, we can distinguish different motivational constellations, for example, in the following two goals: 
Goal One: Graduating high school. It is a goal to which students attach great importance (a very low standard deviation indicates a strong consensus in this regard). Also, perceived instrumentality of learning is high. Dominance has an internal controllable attribution (hard work). The most important variable for success in variable regression analysis shows instrumentality, but also the variable of internal attributions. This also finds confirmation through factor analysis, where the first factor is made up of students with good grades, high instrumentalisty, internal attributions and attributed importance to this goal, whereas the second factor is more typical of students with poor grades, who also attach great importance to goal one, but they tend to attribute it to external influences (mood, happiness). In other words, they all want to graduate from high school, but achieving this goal is only possible when the students are willing to make an effort to set this goal and perceive studying as a means of achieving this goal.

Goal Two: Graduating from university. The importance of this goal is relatively low for students, although a moderately large standard deviation indicates differences of opinion. Instrumentality of studying to accomplish this goal is perceived as relatively high. Strong position has internal attributions. As shown by the regression analysis, the dominant role in this case probably has the importance of the goal. Factor analysis describes only one factor, which is consistent with this finding: it is characteristic of students with good grades who ascribe high importance to this goal, and it also attributes accomplishing this goal to internal controllable causes. They are able to see studying as a tool for achieving this goal.

\section{CONCLUSION}

The issue of time perspective and its operationalization is very complex and requires a lot of creativity. In our research, we have addressed the following issues: the relationship of time perspective and achievement motivation, the role of will in time perspective, as well as an instrumental value of studying for future goals. In addition, we are working on adapting the coding system of the Motivational Induction Method and on validating the Perspective Orientation method.

In conclusion, we would like to discuss the relationship between time perspective and one's „well-being". Time perspective can influence attention, perception and decision making, but it can also have a strong influence on all aspects of human behavior. To fulfill the goals and plans connected with school, but also with the working and social environments, it is essential to adopt a developed (extended) future time perspective. Individuals oriented to the future, however, may feel that they do not devote enough time to hobbies or their families, and hence their inability to fully enjoy the present moment spent in activities outside of school or work.

\section{REFERENCES}

Cottle, T. (1976). Perceiving Time: A Psychological Investigation with Men and Women. New York: John Wiley and Sons.

Gjseme, T. (1974). Future Time Orientation As A Function Of Achievement Motives, Ability, Delay Of Gratification, And Sex. The Journal of Psychology, 173-188. 
Gjseme, T. (1983). Introduction: An Inquiry into the Concept of Future Orientation. International Jurnal of Psychlogy, 18, 347-350.

Gjseme, T. (1983). On the Concept of Future Time Orientation: Considerations of some functions' and measurements' implications. International Jurnal of Psychlogy, 18, 443-461.

Four phases of Rubicon model, Retrived April 27, 2013, from http://esr.oxfordjournals.org/content/ early/2010/05/23/esr.jcq020/F1.large.jpg

Havlíčková, R. (2011). Využití MIM při diagnostice časové perspektivy [Using MIM in Time Perspective Diagnostic]. Praha: PedF UK.

Heckhausen, H. (1991). Motivation and action. New York and Berlin: Springer-Verlag.

Husman, J. \&, Lens, W. (1999). The Role of the Future in Student Motivation. Educational psychologist, $34(2), 113-125$.

Hrabal, V., \& Man, F., \& Pavelková, I. (1989). Psychologické otázky motivace ve škole [Psychological Questionsof Motivation at School]. Praha: SPN.

Hrbáčková K.(Ed.). (2010). Kognitioní a nonkognitioní detrminanty rozvoje autoregulace učení studentů [Cognitive and noncognitive determinants of development of autoregulation of studying]. Brno: Paido.

Lens, W. (1981). Cognition of Human Motivation and Learning. Leuven: Leuven University Press.

Levine, R. (2006). A Geography of Time. Oxford: Oneworld Publication.

Lewin, K. (1935). A Dynamic Theory of Personality. New York: McGraw-Hill.

Linley, P.A., \& Joseph, S. (Eds.). (2004). Positive Psychology in Practise. Hoboken, NJ, USA: John Wiley \& Sons, Inc.

Nuttin, J. (1980). Future Time Perspective and Motivation. Leuven: Leuven University Press.

Nuttin, J. (1980). Motivation, Planning, and Action. Leuven: Leuven University Press.

Pavelková, I. (2002). Motivace žákủ k učení. (Perspektivní orientace žákủ a časový faktor v žákovské motivaci) [Students'motivation for studying. (Perspective Orientation and The Time Factor i students'motivation)]. Praha: UK.

Pavelková, I. (1990). Perspektivní orientace jako činitel rozvoje osobnosti [Perspective Orientation As a Factor For the Development of Personality]. Praha: Academia.

Pavelková, I. (2010). Motivace jako předpoklad vzdělávací autoregulace [Motivation as a prerequisite for self-education]. In: K. Hrbáčková (Ed.), Kognitioní a nonkognitioní detrminanty rozvoje autoregulace učení studentù [Cognitive and noncognitive determinants of development of autoregulation of studying] (pp. 73-90). Brno: Paido.

Pavelková, I., Purková, V., \& Menšíková, V. (2010). Časová perspektiva jako významný regulativ v lidském životě a žákovské motivaci [Time perspective as a significant regulator of the human life and student motivation]. Studia Paedagogica. 15(1). 29-45.

Pavelková, I., \& Menšíková, V. (2009). Vztah studentů k budoucnosti [Students relationships for the future]. Premeny psychológie v evropskom prostore [The Transformation of Psychology in Europien Area], Bratislava: SAV.

Roeckelein, J. (2000). The Concept of Time in Psychology. London: Greenwood Press.

Seijts, G. (1998). The Importance of Future Time Perspective in Theories of Work Motivation. The Journal of Psychology, 154-168.

Vygotskij, L.S. (1976). The Development of Higher Psychological Processes. Praha: SPN.

Zimbardo, P., \& Boniwell, I. (2004). Balancing One's Time Perspective in Pursuit of Optimal Functioning. In: P.A. Linley, \& S. Joseph, S. (Eds.), Positive Psychology in Practise (pp. 2-23). Hoboken, NJ, USA: John Wiley \& Sons, Inc.

Zimbardo, P., \& Boyd, J. (1999). Putting Time in Perspective: a Valid, Reliable Individual-Differences Metric. Journal of Personality and Social Psychology,77/6, 1271-1288.

Zimbardo, P., \& Boyd, J. (1999). Time Paradox. New York: Rider.

Zimbardo, P., Boyd, J, \& Keough, K. (1999). Who's Smoking, Drinking, and Using Drugs? Time Perspective as a Predictor of Substance Use. Basic and Applied Social Psychology, 21(2), 149-164.

Zimbardo, P. (1996). The Zimbardo Time Perspective Inventory (ZTPI) Psychometric and Scoring Key. Stanford: Preselection. 